\title{
New Marketing Inspired by Blind Box
}

\author{
Ruijing Zhao ${ }^{1, \text { a, }{ }^{*}, \dagger}$, Jiayi $\mathrm{Xu}^{2, \mathrm{~b},{ }^{*}, \dagger}$ \\ ${ }^{1}$ Business School, East China University of Science and Technology, Shanghai, China \\ ${ }^{2}$ International class, Jinan Xinhang Experimental Foreign Language School, Jinan, China \\ "Corresponding author.Email: ${ }^{a} 10183157 @$ mail.ecust.edu.cn, ${ }^{b} 3442467832 @ q q . c o m$ \\ These authors contributed equally.
}

\begin{abstract}
With the increasing variety of products, the gap between them is getting smaller and smaller. People pay more and more attention to marketing in order to make products out of the lead. Based on this, this paper takes the most popular blind box as an example to discuss its marketing strategies, including uncertainty, hunger marketing, joint name and fan effect of IP, Demand driven by social communication, etc., to analyze how to better take the advantages and values of the product in the communication. At the same time, as a new product, blind box also has some shortcomings such as over marketing and inadequate supervision.
\end{abstract}

Keywords: blind box, marketing strategy, supervision.

\section{INTRODUCTION}

With the development of economy, the market is becoming more and more diversified. Many new industries have sprung up in an endless stream, and the blind box has appeared before the public. Blind box as a new sales model is becoming more and more intense. The market for blind boxes is expected to reach 30 billion yuan by 2024 , according to data from an industry report. The largest listed company in the blind box, Popmart, has a market value of more than HK $\$ 100$ billion. The success of blind boxes cannot be separated from good marketing methods. The difference between this paper and the paper we collected lies in the fact that we combined a variety of marketing strategies from different perspectives and analyzed the content of each marketing strategy more specifically. And take a specific blind box company -Popart as an example to make the analysis and data more reliable; Starting from People's Daily life to arouse more people's resonance.

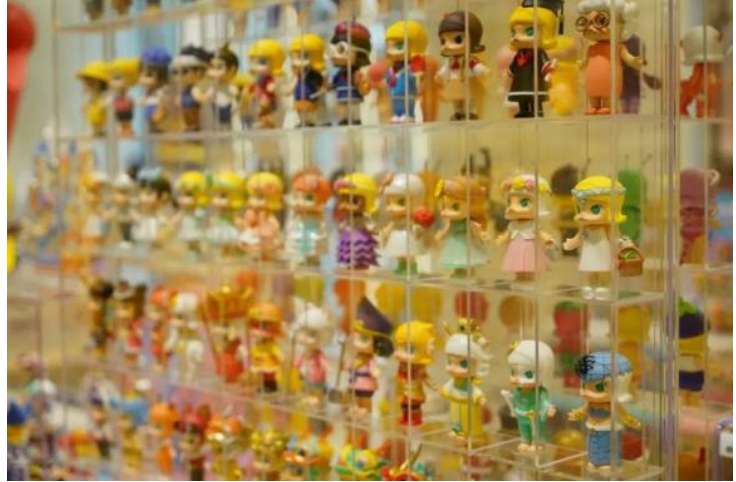

Figure 1. A variety of blind boxes

\section{MARKETING STRATEGIES IN BLIND BOXES}

\subsection{The stimulus of uncertainty}

At first, blind box marketing was used in two dimensions, and the target customers were people who were obsessed with the brand. Blind boxes take advantages of customers' psychology of pursuit of stimulation. When facing with unknown blind boxes, what consumers expect is their favorite IP, which gives the product with higher emotional value. Merchants change the product consumption into emotional consumption so that customers are willing to pay higher prices for their favorite IP [1].The essence of such marketing strategy is to make consumers addicted in their 
products. The addictive point lies in the uncertain revenue, which enables consumers to have gambler psychology and be obsessed with this purchasing behavior. At the same time, it also makes use of collecting fetish to stimulate them to collect a complete set to achieve consumption.

\subsection{Hunger marketing}

Hunger marketing as a marketing tool is now hot. Taking the sales of blind boxes as an example, many blind boxes are put on sale and pre-sold regularly, which makes people worry that they will have no idea if they buy late. Besides, more and more blind boxes are sold in limited quantities, such as Christmas gift boxes [2]. To grab the desired blind box, people will look for the agent to grab the blind box instead of themselves. Therefore, people have brought the illusion that demand exceeds supply. The manufacturers of blind boxes show the scarcity of blind boxes to the public, and absence leads to competition and choice [3]. More and more merchants begin to use "hunger marketing" to create the illusion that the output is small and the demand is short, and then raise their prices to earn a lot of profits and finally set up the image of a high-value brand for people. In addition, the blind box sets the hidden money, the probability of the draw is almost zero. They are causing people to spend a lot of money on a hidden money box. In the tide to play on the individual hidden blind box even fry to the price of 800 yuan. Compared with its original price of 58, the price has turned over several times. The rarer the blind box and the hand have a great appreciation space, for example, Labubu astronaut, Molly Nutcracker, and another hidden style in the average market price of more than 2,000 yuan. Every consumer will have the opportunity to take out the hidden at the price of around 50 yuan; although the probability is very small, many people will still try. This small probability and a small amount of hidden money aroused people's desire to buy and spawned some groups of hidden reselling behavior. Created belongs to the blind box of capital circulation mechanism. Therefore, the application of hunger marketing in blind boxes is undoubtedly very successful. Therefore, more and more businesses begin to imitate the use of hunger marketing in blind boxes to improve their profits.

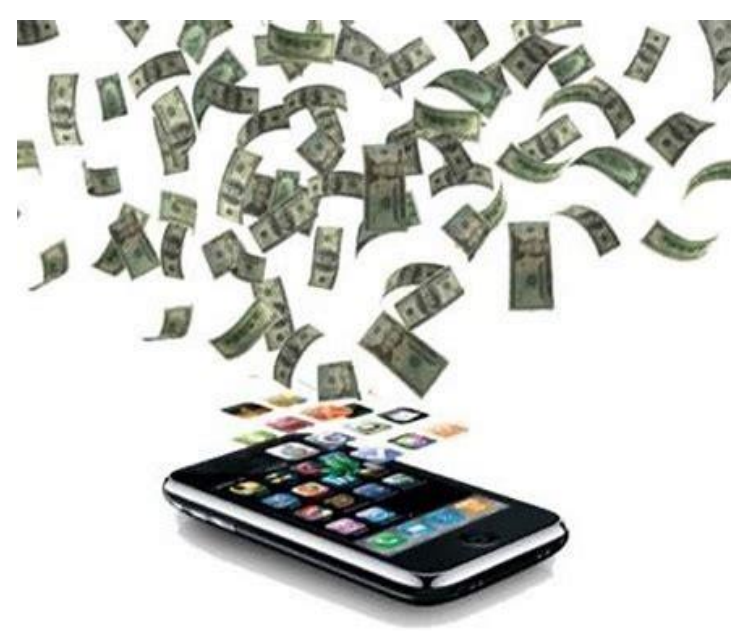

Figure 2. People are tempted by internet hunger marketing to buy products.

\subsection{Joint name and fan effect of IP}

Many brands we are familiar with will have their own spokespersons, such as the former Nike spokespersons Wang Yibo, China Li Ning spokespersons Xiao Zhan and so on. Previously, when we searched the famous Chinese sneaker website for Wang shoes, we found hundreds of pairs of Nike shoes bearing the same name. The shoes he wears are often worth many or even several times their selling price. This brings us to the so-called fan effect. The so-called "fan circle" is the invisible hand that drives the fan economy. When a product is linked to a star, his fans will quickly get the same item. However, different stars will have different fan effects, so the brand is also very important when choosing spokespersons. A brand that can bring a lot of profits is often high traffic stars. The biggest stars of the moment are also the best at bringing goods. In the current situation where there are many substitutes, people will love the brand with their favorite spokespersons more than the original appearance of the product. As for the blind box, we can clearly see that the price and sales of the blind box rose sharply after the live broadcast of the star. Many fans who originally did not buy blind boxes also began to buy blind boxes. In addition, IP co-branding creates more value than the product itself. For example, blind boxes will come from different brands such as Dimo, Harry Potter, and the Inhuman series. Many of these IPs themselves have a huge number of fans, so the consumer groups they bring to the brand are also huge. Different products will also bring people a sense of freshness. Different series of different joint names brought by the sense of freshness is no longer stimulating consumers to buy desire. Therefore, under the influence of IP, the popularity will reach a higher level. 


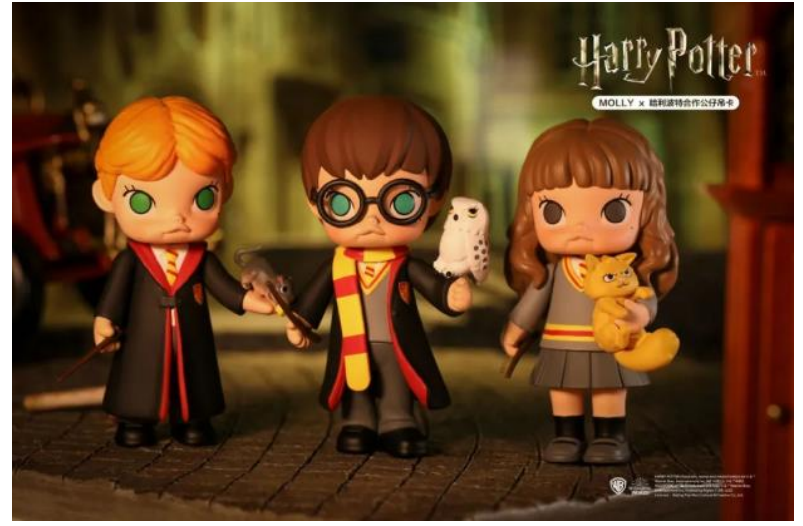

Figure 3. Bubble Mart and Harry Potter joint model, MOLLY and Harry Potter

\subsection{Demand driven by social communication}

Generation $\mathrm{Z}$ is the main customer to buy blind boxes. Such a group of energetic young people is driving the great changes in the consumption structure and market of China. Generation $\mathrm{Z}$ was born in a world of abundant material, and most of them were well-educated and skilled at Internet. With the upgrading of consumption, Generation $\mathrm{Z}$ was more willing to pay for their interests than other age groups. Generation $\mathrm{Z}$ grew up in the company of comics, animation and games. As a representative derivative of two dimensions, the blind boxes will be more and more popular among young people.

This change in the meaning of consumption gives blind boxes a certain social attribute. Due to the low probability of getting specific products, people can be induced to share their emotions caused by unwrapping the blind box on their social network.Meanwhile, consumers will also be keen to exchange with others through the Internet when they get repeated products or unsatisfactory products. The secondary market is formed spontaneously, making blind boxes become the new social currency for consumers [4]. According to the data from second-hand trading platform Xianyu, the number of blind box players on Xianyu has exceeded 300,000 in 2019 , which shows that blind box marketing is largely driven by social relationships between customers.

Large-scale exhibitions can also reflect the offline social contact of blind boxes, among which the most famous ones are International Fashion Toy Fair in Beijing and Shanghai hosted by Popmart. More than 300 artists and brands participated in the exhibition, which attracting the attention of customers from all over the world and further promoting the popularity of blind boxes [1].

\section{THE PROBLEM OF BLIND BOX ECONOMY}

\subsection{Over Marketing}

Behind the benefits of the blind box, marketing is a dark side. The essence of blind box marketing is mysterious. Behind the unknowable content of the blind box, it is easy to distort the market trading rules. Some operators, to bask on the heat of the blind box, exaggerate the value of goods, fictitious quality probability, or sell inferior goods, take the opportunity to clear the inventory [5]. What's more, the sale of live animals in blind boxes not only poses health and safety risks but also violates the bottom line of laws and regulations in health quarantine, postal transportation, and other aspects. Some consumers said that they bought a live animal blind box but received a dead animal, and the "surprise" became "shock." All this not only harms the legitimate rights and interests of consumers but also disrupts the regular order of the market, which is not conducive to the healthy development of the industry. Over-marketing of blind boxes seriously endangers people's living environment and safety [6]. Marketing itself promotes economic and social development, but excessive marketing will lead to the disorderly expansion and even savage growth of the blind box market, just like opening Pandora's box, which is easy to produce a variety of potential consequences and unpredictable disasters [7]. The box can not be transparent, and the market must not be transparent. It must solve the legality, fairness, security issues. Therefore, it is necessary to improve relevant laws and regulations as soon as possible, strengthen market supervision according to law, explore the introduction of third-party supervision mechanism, timely cleanup, and the crackdown on all kinds of behaviors that exceed the bottom line, so as to improve the standard level of the blind box industry and let the light of the rule of law into this emerging market. So marketing can but not too much.

\subsection{Inadequate Supervision}

Due to the imperfect supervision measures for blind boxes at present, there are many "problem blind boxes" in the market. The quality of these blind boxes is uneven, inferior and counterfeit products often appear, and some merchants even use blind boxes to clear inventory, making blind boxes become a method for merchants to deceive consumers [8]. First of all, not everything is suitable as a blind box [9].Secondly, the goods in the blind box must comply with the legal provisions, meet the legal quality requirements and meet the legal sales conditions. Therefore, the supervision and regulation of the blind box must run through the whole business of the blind box. On the one hand, it is necessary to clarify the supervision and supervision responsibility of blind box business as soon as possible, and make clear the subject 
of responsibility [10]. On the other hand, the relevant industry standards should be issued as soon as possible to make the blind box business have rules to follow and laws to follow. At the same time, improve the access threshold of blind box business, strengthen the control of packaging, circulation and other key links. In this way, the number of "problem boxes" will be reduced.

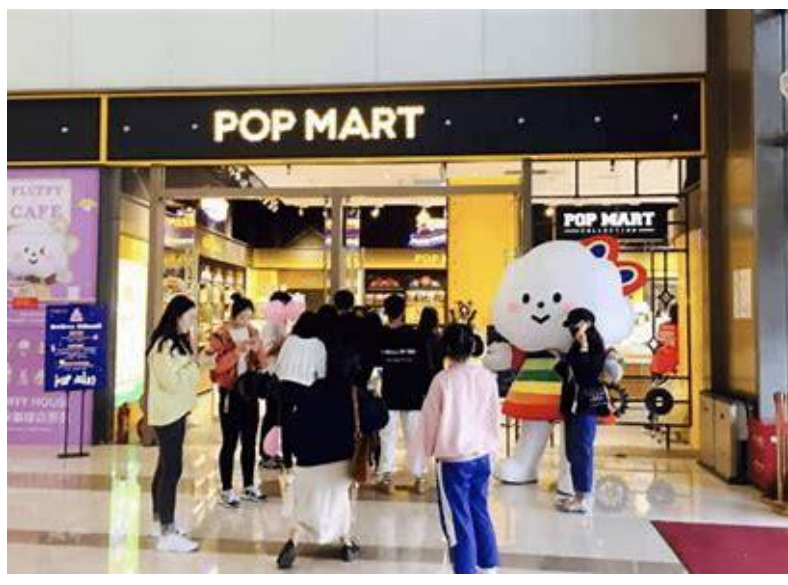

Figure 4. Receiving attracted customers in front of the store

\section{CONCLUSION}

The popularity of blind boxes makes us pay more attention to its marketing strategy. With the continuous upgrading of consumption, consumers are no longer satisfied with material consumption, but more eager for emotional and spiritual satisfaction, hoping to feel pleasant through their consuming behavior. The stimulus of the uncertainty and hunger marketing strategy used by merchants have established a highly addictive mechanism, which makes consumers constantly pay for their emotions. Meanwhile, IP and fan economy greatly promote the marketing of blind box, giving it more value than the product itself. Now, blind box has become a symbol of young individuals' personality and has important social significance. To some extent, the marketing strategies of blind box indicate the development direction of marketing in the future. Merchants should seize the spiritual consumption needs of consumers and make marketing strategies more targeted. At the same time, there are some problems in the blind box marketing. To solve the negative problems in the blind box craze, it depends on the joint efforts of all social forces, including merchants and consumers.

\section{REFERENCES}

[1] Ruyi Ji. "Psychological analysis of "blind box craze" consumption from the perspective of Internet communication" Southeast communication No.185.01(2020):126-128.

[2] Zeyuan Zhang.Study on consumers' purchasing intention of blind box products based on Logistic regression model[ $\mathrm{J}]$.the Chinese market, 2020(25):125-126+131.

[3] Qi Su.Tide plays the first secret, Bubble Mart's windfall business[J].Modern Commercial Banking,2020(14):76-79.

[4] Yan Lin,and Haifeng Ma."Why does "blind box" drive people crazy" Journal of Social Science 201911-28,006, cultural criticism .

[5] Yin Wei. Blind boxes are not regulatory blind spots[N]. China Discipline Inspection and Supervision News, 2021-02-09(002).

[6] Jiayan Wang. Blind box "fire out of the circle" supervision should also follow[N]. Suzhou Daily,2021-03-16(A08).

[7] Shujia Li. Blind boxes cannot become regulatory "blind spots"[N]. Hebei Daily,2021-03-29(003).

[8] Jiawei Chen."Research on product communication and marketing -- taking blind box as an example." International public relations .10(2020):295-296. doi:10.16645/j.cnki.cn11-5281/c.2020.10.145.

[9] Jun Wen."Blind box economy, why popular young people chase after?" China Audit Newspaper 202012-14,007, Consumer finance.

[10] Xinyue Han."A view of the puzzle of the blind box economy from the perspective of behavioral economics." Business Information.27(2019):117118. doi:CNKI:SUN:SYJW.0.2019-27-075. 